\title{
EMISSION TESTING OF CATALYTIC CONVERTER USING ZIRCONIUM OXIDE (ZrO) AND COBALT OXIDE (CoO) AS CATALYST
}

\author{
RAJAT KUMAR ${ }^{1}$, SUPREET SINGH ${ }^{2} \&$ MANPREET KAUR ${ }^{3}$ \\ ${ }^{1,2}$ Department of Automobile Engineering, Chandigarh University, Mohali, India \\ ${ }^{3}$ Department of Mechanical Engineering, BBSBEC Fatehgarh Sahib, India
}

\begin{abstract}
In today's scenario, the population of vehicles is increasing day by day. These vehicles are either running on gasoline or diesel engine. Due to abnormal combustion in SI and CI engine, the $\mathrm{NO}_{x}, \mathrm{CO}$ are the two major pollutants which emit from the exhaust. We can control this problem by pre-exhaust and after-exhaust treatment. Numbers of technologies like improvement in engine design, fuel pre-treatment, use of alternative fuels, fuel additives, exhaust treatment or better tuning of the combustion process etc. are being considered to reduce the emission levels of the engine. Among all the types of technologies developed so far, the most suitable after exhaust technique is the catalytic converter. This research work presents the characteristics of a new catalytic converter to be used for reduction of emissions. Others had designed and fabricated two types of catalytic converter, i.e. based on the material and type of wire mesh used. The present work aimed at using zirconium oxide $(\mathrm{ZrO})$ and Cobalt Oxide $(\mathrm{CoO})$ as a catalyst for catalytic converter. To determine the emission contents from LPG and Petrol, Eco- Gas Analyzer 100 was used. The experiment was conducted separately for both coated square type wire mesh and coated diagonal type wire mesh catalytic converter. From all the experimental data and graphical representation, it is observed that the reduction in pollution content, in case of coated diagonal wire mesh is much higher than that of coated square wire mesh type catalytic converter for both LPG and Petrol engine.
\end{abstract}

KEYWORDS: Exhaust Emission, Catalytic Converter, Oxidation and Reduction Process, Gas Analyzer \& Wire Mesh

Received: May 18, 2017; Accepted: Jun 05, 2016; Published: Jun 15, 2017; Paper Id.: IJMPERDJUN201733

\section{INTRODUCTION}

\section{Catalytic Converter}

The catalytic converter significantly reduces the amount of harmful gases. The hot gases along with hydrocarbons $(\mathrm{HC})$ Carbon Monoxide $(\mathrm{CO})$ and oxides of Nitrogen $\left(\mathrm{NO}_{\mathrm{x}}\right)$ which are harmful to the environment sent to the exhaust manifold through the exhaust valve. Exhaust gases are passed from exhaust manifold to the catalytic converter through a pipe. The catalytic converter reduces the toxicity of these gases with the help of a catalyst. There are basically two types of catalytic converter naming 2-way and 3-way. In 2-way CC only, Oxidation of gases will take place as shown in equation 1

$2 \mathrm{CO}+\mathrm{O}_{2} \quad 2 \mathrm{CO}_{2}$

This reaction is Oxidization of the Hydrocarbon

In 3-way Oxidation and Reduction both take simultaneously as shown in equation 2 
$2 \mathrm{NO}_{\mathrm{x}} \quad \mathrm{N}_{2}+\mathrm{XO}_{2}$

This reaction is Reduction of the Nitrogen Dioxide

The best way to control the exhaust gas emission is the use of metal monolith. There are various reasons behind using of metal monolith instead of ceramic duct including economy, availability of platinum group (Noble Metal) and the operating conditions of using platinum group based catalytic converter emphasizes the investigation of Non Noble based catalyst material.

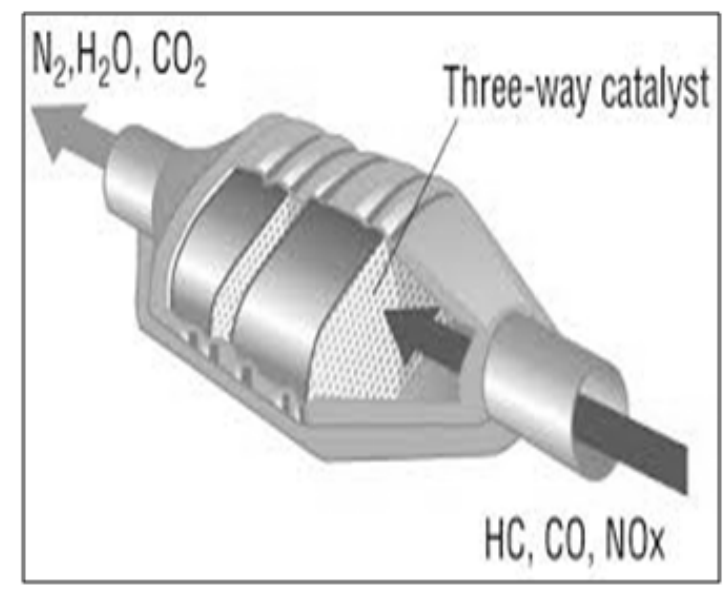

Figure 1: Basic Catalytic Converter

Nowadays, in automobile sector, widely used catalysts are Platinum, Rhodium and Palladium. These are very high cost catalysts. Due to this reason, the final cost of the catalytic converter also has become very high. In this research, work catalysts used are of Cobalt Oxide $(\mathrm{CoO})$ and Zirconium oxide $(\mathrm{ZrO})$ i.e. these catalysts are low cost ones and absorb harmful pollutants. Authors have fabricated Catalytic Converter using the stainless steel wire mesh instead of honey comb ceramic duct. Similar research was done by M A Kalam et. Al. [4] Based on catalyst materials consisting of metal oxides such as titanium dioxide $\left(\mathrm{TiO}_{2}\right)$ and cobalt oxide $(\mathrm{CoO})$ with wire mesh substrate. The catalyst materials were inexpensive in comparison with conventional catalysts (noble metals) such as palladium or platinum. It is experimentally found that the conversion efficiencies of $\mathrm{TiO}_{2} / \mathrm{CoO}$ based $\mathrm{CC}$ are $93 \%, 89 \%$ and $82 \%$ for $\mathrm{NO}_{x}, \mathrm{CO}$ and $\mathrm{HC}$ emissions respectively. In their results $\mathrm{TiO}_{2} / \mathrm{CoO}$ based catalytic converter, reduced higher $\mathrm{NO}_{\mathrm{x}}, \mathrm{CO}$ and $\mathrm{HC}$ emissions in comparison to earlier catalytic converters.

\section{EXPERIMENTAL PROCEDURE}

Wire mesh is fabricated as per the size of the catalytic converter. Stainless steel 304 wire mesh of square and diagonal shape is used as the substrate material in the fabrication of the catalytic converter.

A total of 50 pieces is taken in the circular shape of diameter $8.0 \mathrm{~cm}$ and are arranged in straight bars. The length of the stainless steel wire mesh is around $15.0 \mathrm{~cm}$. The gap between each circular wire mesh piece is around $0.2 \mathrm{~cm}$ which is maintained by using the washer. Alumina and silica powder are used as the wash coating material for the coating of substrate to increase the irregular surface area of the wire mesh. Zirconium based catalytic converter is prepared with the $90 \mathrm{~g}$ of Alumina silica powder and $10 \%$ Zirconium oxide. Zirconium oxide and cobalt oxide are used as a metal catalyst. It is mixed through the magnetic stir. The pure cobalt oxide is used as the reducing agent and zirconium oxide ( $\mathrm{ZrO})$ is using 
as oxidizing agent. Wire mesh cleaning with the $10 \%$ of HCL solution for 30 minutes and then rinsed in distilled water before being dried in oven at temperature of $100^{\circ} \mathrm{C}$. After preparing the slurry, the wire mesh pieces are dipped in the slurry by dipping technique. Finally prepared wire mesh pieces are then dried in oven at temperature of $120^{\circ} \mathrm{C}$ for $12 \mathrm{~h}$ before Calcinations.

\section{Materials Required for Current Research Work}

Material required for the fabrication of the new Catalytic Converter is a Square type wire mesh, Diagonal type wire mesh, Distilled water, concentrated HCL Chemical catalyst i.e. Silica powder, Alumina powder, Zirconium Oxide and Cobalt Oxide.

Table 1: Properties of Catalyst Used

\begin{tabular}{|l|c|c|c|c|}
\hline \multicolumn{1}{|c|}{ Material Used } & B. $\mathbf{P .}{ }^{\circ} \mathbf{C}$ & M. P. ${ }^{\circ} \mathbf{C}$ & ${\text { Density } \mathbf{G} / \mathbf{C m}^{3}}$ & T.C. W/Mk \\
\hline Zirconium Oxide & 1975 & 1975 & 5.6 & 3 \\
\hline Cobalt Oxide & 900 & 895 & 6.1 & 100 \\
\hline Alumina & 2977 & 2072 & 4.1 & 30 \\
\hline Silica & 2950 & 1713 & 2.1 & 12 \\
\hline
\end{tabular}

\section{Designing of Catalytic Converter}

Solid works is using for the designing of each component of catalytic converter.

B.P. - Boiling point, M.P- Melting Point, T.C- Thermal Conductivity

Table 2: Parameters of Monoliths

\begin{tabular}{|c|c|l|c|}
\hline Diameter in cm & Shape & Cell Shape & Wire Mesh \\
\hline 8.0 & circular & Square & 16 \\
\hline 8.0 & circular & Diagonal & 16 \\
\hline
\end{tabular}

\section{Casing}

It is the outer part of the catalytic converter. The material which we are using is Mild steel, because of its good physical and thermal properties like high melting point, strength. The length of the casing was around $20 \mathrm{~cm}$. As shown in figure 2.

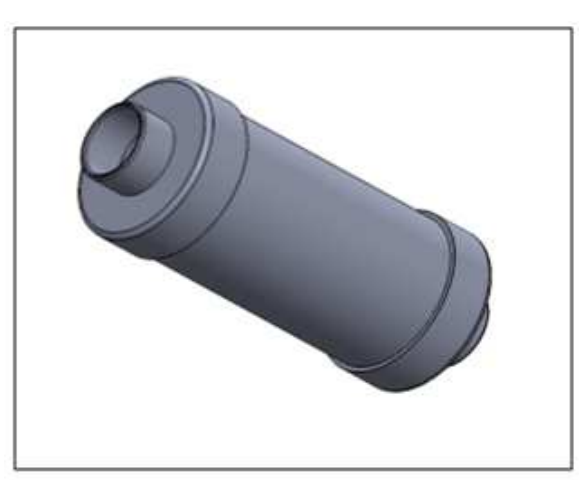

Figure 2: Catalytic Converter

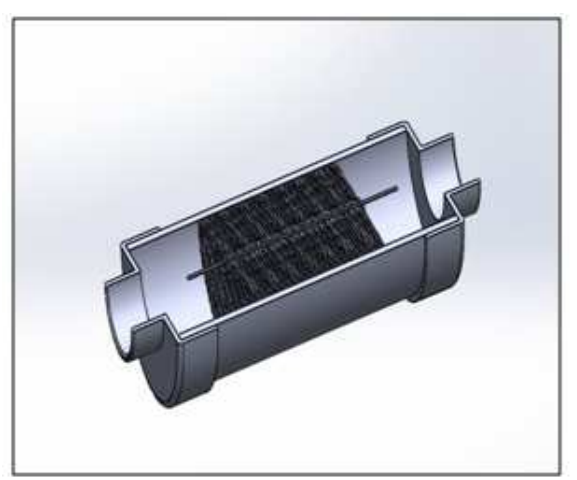

Figure 3: Cut Section of Catalytic Converter

Rod

In this experimental work, 50 pieces of wire mesh were arranged in a long straight bar. The length of arranged wire mesh was around $15 \mathrm{~cm}$. as shown in figure 4. 


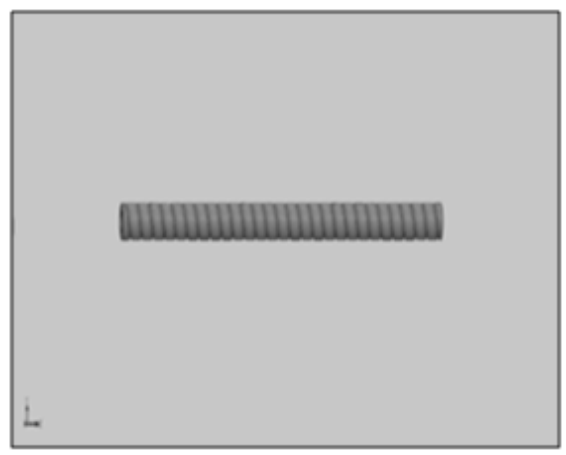

Figure 4: Rod

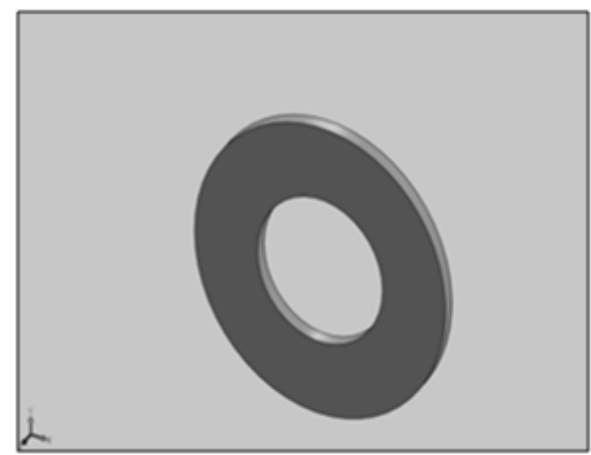

Figure 5: Washer

\section{Washer}

In fabricated catalytic converter, the gap between each of wire mesh piece was around $0.2 \mathrm{~cm}$ which is produced by using the washer as shown in Figure 5.

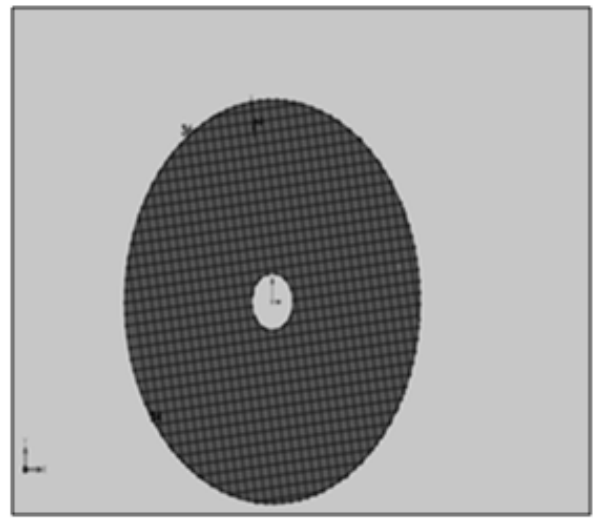

Figure 6: Wire Mesh Peace

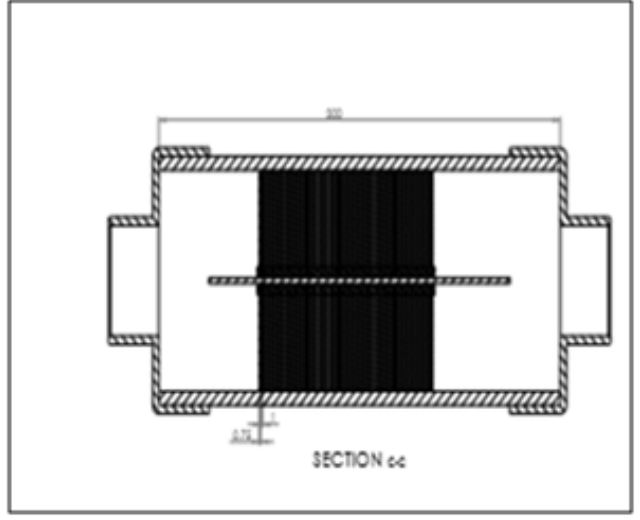

Figure 7: Designed Wire Mesh Arrangement

\section{Wire Mesh Pieces}

Wire mesh pieces used as substrate material in the catalytic converter. The material for wire mesh is Stainless Steel because of the advantage of physical and thermal properties as well as low cost. The diameter of the circular piece was around $8.0 \mathrm{~cm}$ of both Square and Diagonal type as shown in Figure 6.

\section{Preparing Stirring Mixture}

It is prepared by mixing chemical alumina, silica solution in which Zirconium oxide ( $\mathrm{ZrO})$ and Cobalt Oxide $(\mathrm{CoO})$ used as catalyst for increasing the rate of reaction to control the harmful pollutants namely $\mathrm{CO}, \mathrm{CO}_{2}, \mathrm{HC}$ and $\mathrm{NO}_{\mathrm{X}}$. These catalysts are responsible for both oxidation and reduction reaction in exhaust gas emissions. These chemicals react with the exhaust and convert toxic gases $\mathrm{HC}, \mathrm{CO}, \mathrm{NO}_{\mathrm{X}}$ into non toxic $\mathrm{H}_{2} \mathrm{O}, \mathrm{CO}, \mathrm{N}_{2}$ and $\mathrm{O}_{2} .90$ grams of Alumina silica solution added to the 10 game of $\mathrm{ZrO}$ to get $10 \%$ Zirconium Oxide $(\mathrm{ZrO})$ slurry. The slurry then stirred at $500 \mathrm{RPM}$ for two hours at $600^{\circ} \mathrm{C}$. Two grams of Cobalt Oxide $(\mathrm{CoO})$ gradually added in the slurry mixture as shown in figure 8 . 


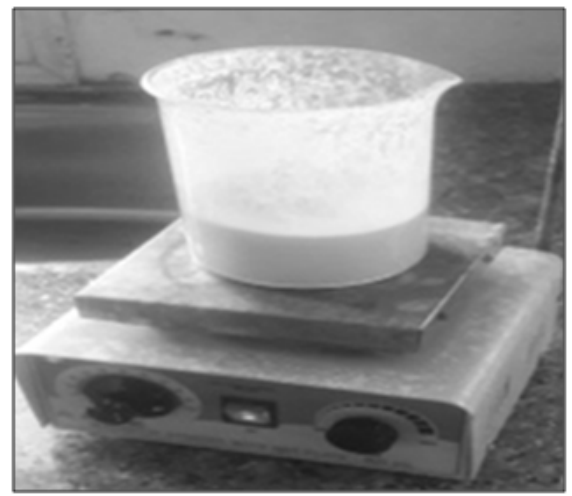

Figure 8: Magnetic Stirring

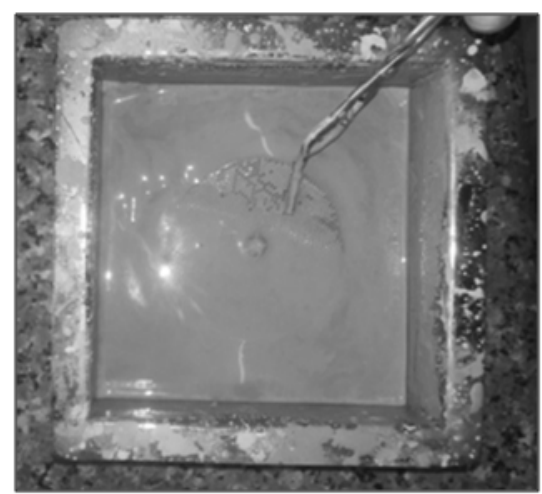

Figure 9: Catalyst Coating

\section{Treatment of Wire Mesh Substrate}

The circular pieces of wire mesh were then immersed into a preparation of $10 \% \mathrm{HCL}$ solution for 30 minutes to remove all the impurities. Then, these wire meshes were rinsed in distilled water before being dried in an oven at temperature of $100^{\circ} \mathrm{C}$. The drying process takes about $1.0 \mathrm{~h}$ before coating it with catalyst.

\section{Substrate Coating}

The stainless steel wire mesh pieces, then coated with the metal catalyst via dipping technique as shown in fig. 9 . After bowered process, coated stainless steel wire mesh was dried in oven as shown in figure 10 at temperature of $120^{\circ} \mathrm{c}$ for $6.0 \mathrm{~h}$ before being claimed in a muffle furnace.

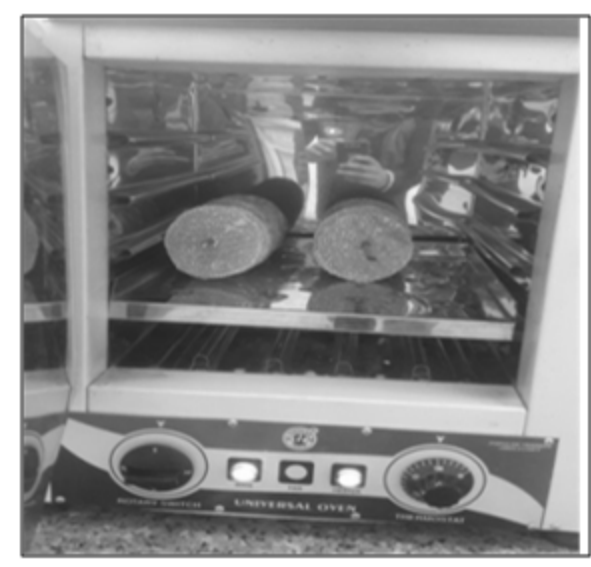

Figure 10: Heating in Oven

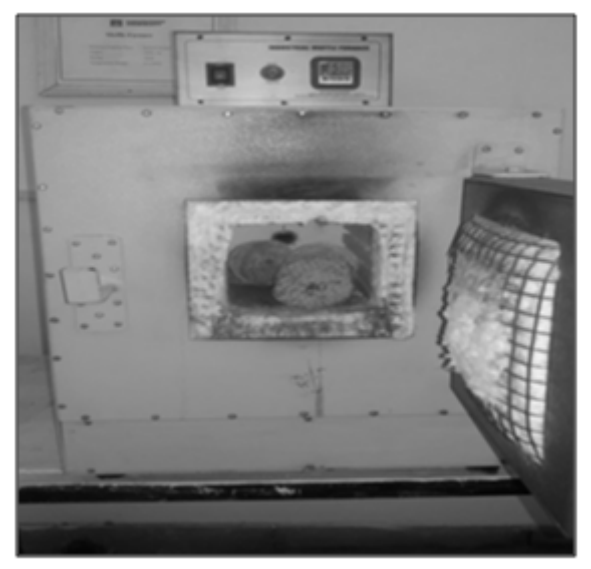

Figure 11: Calcination in Muffle Furnace

Calcination is a process in which a material is heated to a high temperature and the volatile material is expelled. Calcination take $4.0 \mathrm{~h}$ at a temperature of $550^{\circ} \mathrm{c}$ with temperature ramping up on $10.0^{\circ} \mathrm{c} / \mathrm{min}$ and holding time of 300 minutes as shown in figure 11. After the calcination process, the stainless steel wire mesh arranged into a straight bar to become a substrate for use as a catalytic converter. 


\section{Fabrication of Catalytic Converter}

Table 3: Catalytic Converter Dimensions

\begin{tabular}{|l|c|}
\hline Specifications & Dimensions \\
\hline Length of Casing & $20 \mathrm{~cm}$ \\
\hline Diameter of Casing & $8 \mathrm{~cm}$ \\
\hline Inlet diameter of Reducing Coupling & $5 \mathrm{~cm}$ \\
\hline Outlet diameter of Reducing Coupling & $8 \mathrm{~cm}$ \\
\hline Inlet diameter of Reducer & $3 \mathrm{~cm}$ \\
\hline Outlet diameter of Reducer & $5 \mathrm{~cm}$ \\
\hline
\end{tabular}

The stainless steel wire mesh of both square and diagonal shapes were cut into the circular pieces of the die. $8 \mathrm{~cm}$ as shown in figure 12.

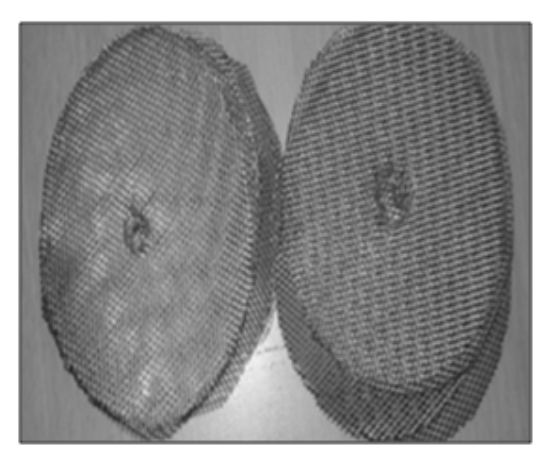

Figure 12: Wire Mesh Pieces

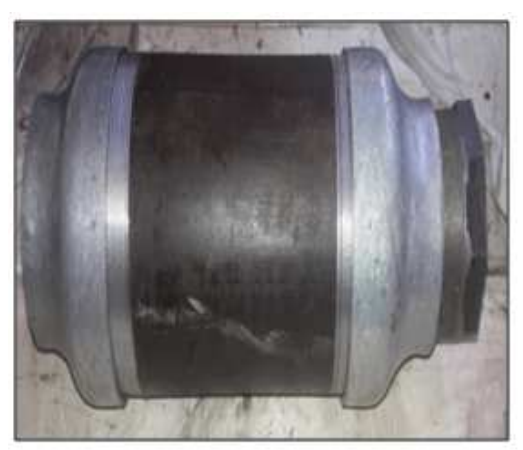

Figure 13: Fabricated Catalytic Converter

Total 50 pieces coated with the catalyst were arranged on to a straight bar. The total length of the SS-304 wire mesh arrangement was around $15.0 \mathrm{~cm}$. As shown in figure, the gap between each piece of stainless steel wire mesh was around $0.2 \mathrm{~cm}$ and was created by using the washer. Finally the catalytic converter with catalyst coating has been successfully fabricated as shown in figure 13.

\section{Experimental Setup and Procedure}

\section{Engine Setup for LPG Engine}

A single twine spark plug, 4-stroke DTSi engine was used to collect the data. The rated power was $8.5 @ 6000$ (KW@ @PM). Detailed specification of the engine is given in the table 1. Smoke meter five- gas analyzer was used to measure the pollution content as shown in figure 9.

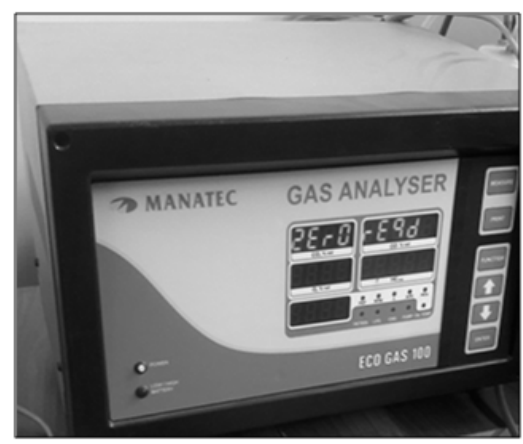

Figure 14: Gas Analyzer 
A probe was mounted at the end of the tail pipe, which supplies the sample of exhaust gas to the smoke meter as shown in figure 10.

Table 3: Engine Specification (LPG)

\begin{tabular}{|l|l|}
\hline Type & Twine Spark Plug, 4-stroke DTSi \\
\hline Maximum Power & $\underline{8.5 @ 6000}$ (Kw @ RPM) \\
\hline Maximum Speed & $65 \mathrm{~km} / \mathrm{h}$ \\
\hline Maximum Torque & $15.2 @ 4250$ ( Nm @ RPM) \\
\hline Displacement & $198.88 \mathrm{cc}$ \\
\hline Number of cylinders & One \\
\hline
\end{tabular}

\section{Engine Setup for Petrol Engine}

A single-cylinder 4-stroke engine was used to collect the data. The rated power is $5.5 \mathrm{Kw}$ at $8000 \mathrm{rpm}$ and the maximum torque is $7.95 \mathrm{~N}-\mathrm{m}$ at $4500 \mathrm{RPM}$. Detailed specification of engine is given in the table 2.Smoke meter five- gas analyzer was used to measure the pollution content. A probe was mounted at the end of the tail pipe which supplies the sample of exhaust gas to the smoke meter.

Table 4: Engine Specification (Petrol)

\begin{tabular}{|l|l|}
\hline \multicolumn{1}{|c|}{ Type } & \multicolumn{1}{c|}{$\begin{array}{c}\text { Air Cooled, 4-Stroke single } \\
\text { Cylinder }\end{array}$} \\
\hline Maximum Power & 5.5 @ 8000 $(\mathrm{Kw} @ \mathrm{RPM})$ \\
\hline Maximum Speed & $87 \mathrm{~km} / \mathrm{h}$ \\
\hline Maximum Torque & $7.95 @ 4500(\mathrm{Nm} @ \mathrm{RPM})$ \\
\hline Displacement & $97.2 \mathrm{cc}$ \\
\hline Number of cylinders & One \\
\hline
\end{tabular}

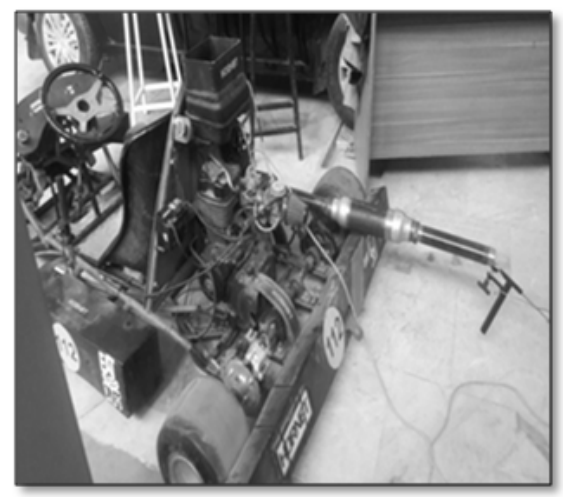

Figure15: Emission Testing on Petrol Engine 


\section{RESULTS AND DISCUSSIONS}

From the Experimental Values, Following Analysis has been made, when LPG is used as fuel

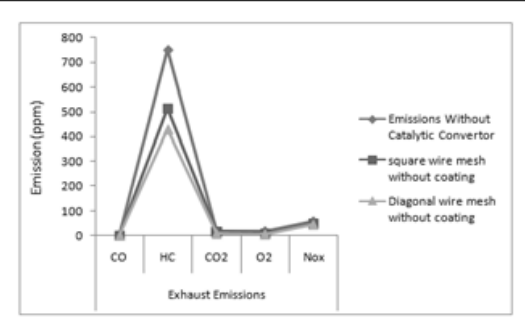

Figure 16: Emission Reductions with Uncoated Wire Mesh

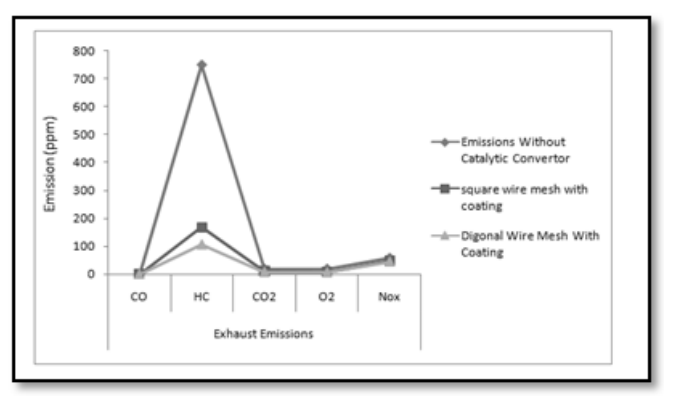

Figure 17: Emission Reductions with Coated Wire Mesh

In current experimentation work, zirconium oxide $(\mathrm{ZrO})$ and Cobalt Oxide $(\mathrm{CoO})$ were used as catalysts for catalytic converter and emission for LPG fuel was compared with and without catalytic convertor for both types of meshes i.e. square wire mesh and diagonal wire mesh. After conducting the experiment on an engine using fuel as LPG, the final results has shown that there is a reduction in emissions by the Catalytic convertor but the Catalytic convertor for square wire mesh without coating has shown a high rate of emissions for $\mathrm{CO}, \mathrm{HC}$, Nox and $\mathrm{CO}_{2}$ as compared to uncoated diagonal wire mesh. Experimental results show that CO emission was reduced by $48 \%$, HC emission was reduced by $66 \%$, $\mathrm{CO}_{2}$ emission was reduced by $52 \%$ and $\mathrm{NO}_{\mathrm{x}}$ emission was reduced to $73 \%$ on an average with the help of uncoated diagonal wire mesh type Catalytic Converter.

From the Experimental Values, following Analysis has been made, when Petrol is used as fuel

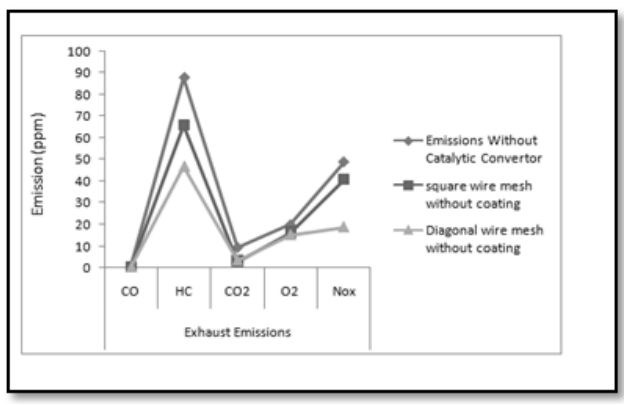

Figure18: Emission Reduction with Uncoated Wire Mesh 


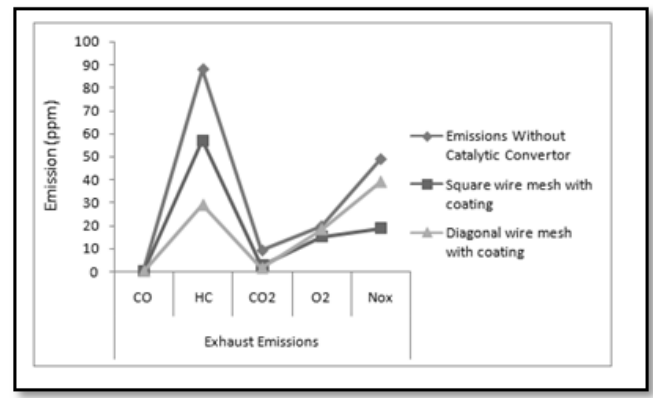

Figure 19: Emission Reductions with Coated Wire Mesh

The petrol engine emits much more amount of pollution content than LPG. After conducting the experiment on Petrol engine, final results show that the $\mathrm{CO}, \mathrm{HC}, \mathrm{CO}_{2}$ and $\mathrm{NO}_{\mathrm{X}}$ emission reduced significantly after the catalytic converter was installed. The reduction in emission with coated diagonal wire mesh is more than that of an uncoated diagonal wire mesh in which percentage reduction of pollution content $\mathrm{CO}, \mathrm{HC}, \mathrm{CO}_{2}$ and $\mathrm{NO}_{\mathrm{X}}$ was $53 \%, 65 \%, 30 \%$ and $39 \%$ respectively.

\section{CONCLUSIONS}

From the experimental result, it has been concluded that the development of cobalt oxide and zirconium oxide based catalytic converter is feasible. Both the experiments on Petrol and LPG engine were conducted in such condition in which readings were not affected by temperature, pressure, moisture, relative humidity. In the above conditions, engine was run at an ideal speed for 5 minutes to make sure that the engine comes into desirable condition which is required and favorable for the experiments. From the above graphs, it is concluded that reduction of $\mathrm{HC}, \mathrm{CO}, \mathrm{CO}_{2}, \mathrm{NO}_{\mathrm{X}}$ to the greatest extent with the help of the catalytic converter. The experiment was conducted separately for both coated square type wire mesh and coated diagonal type wire mesh catalytic converter. It was observed that the reduction in pollution content, in case of coated diagonal wire mesh is much higher than that of coated square wire mesh type catalytic converter.

\section{REFERENCES}

1. D. Karthikeyan, C.G. Saravanan, E. James Gunasekaran (2016), "Performance analysis of catalytic converters in spark ignition engine emission.

2. C. Syed Aalam, Dr. C.G. Saravanan and C. Mohamed Samath (2015). "Reduction of Diesel Engine Emissions Catalytic Converter with Nano Aluminum Oxide Catalyst" International journal for research in emerging science and technology, volume-2, issue-7.

3. Abinesh, J., Arun kumar,J. And Dinesh Kumar, S. (2014) "Minimization of engine emission by using non-noble metal based catalytic converter" International Journal of Development Research Vol. 4, Issue, 11, pp. 2463-2468,.

4. M A Kalam and H M Masjuki, (2009) "Development and test of a new catalytic converter for natural gas fuelled engine", Sadhana, printed in India, Vol-34, pp 467-481, 11.

5. Narendrasinh R. Makwana and Prof. Chirag M. Amin, (2013) "Development and performance analysis of Nickel based Catalytic converter", IJAET, E-ISSN 0976-3945, Vol 4, Issue II, pp. 10-13

6. Series M Pillai, Athul Aravind, Akil R Krishnan, Pranav K (2016) "Modified Catalytic Converter Using Nano Copper and Silver Composite Coating” International Journal of Innovative Research in Science, Engineering and Technology (An ISO 3297: 2007 Certified Organization) Vol. 5, Issue 10. 
7. Manishkumar Parmar, Piyush Patel, Tushar Patel, Gaurav Rathod "Effect of different material and wire mesh size substrate based catalytic converter to reduce exhaust emission", TIJER || ISSN 2349-9249 || Technics International Journal for Engineering VOLUME 1 ISSUE 11

8. RM. Bagus Irawan, P. Purwanto, H. Hadiyanto (2016). “Optimum Design of Manganese-Coated Copper Catalytic Converter to Reduce Carbon Monoxide Emissions on Gasoline, Motor’' Procedia Environmental Sciences 23 (2015) 86 - 92 reduction " International Journal of Advances in Engineering \& Technology.

9. Jay M. Parmar, Prof. Keyur D. Tandel "Performance Analysis of Limestone Coated WIREMESH Catalytic Converter for Emission Control of C. I Engine” IJSRD - International Journal for Scientific Research \& Development| Vol. 1, Issue 11, 2014 | ISSN (online): 2321-0613.

10. R. Yuvaraja, K. Nanthakumar, G. Dhasahinamoorthi (2015) "Development and Performance Analysis of New Catalytic Converter" International Journal of Applications in Mechanical and Production Engineering Volume 1: Issue 6

11. V. Veeraragavan (2013) "Fabrication and Testing of a Catalytic Convertor" International Journal of Applied or Innovation in Engineering \& Management (IJAIEM) Volume 2, Issue 11 